\title{
Concurrent Design Strategy in Modeling and Structure of Electric Scooter for Taiwan
}

\author{
Shih-Wen Hsiao \\ Department of Industrial Design, \\ National Cheng Kung University, \\ Tainan, Taiwan \\ swhsiao@mail.ncku.edu.tw
}

\author{
Chun-Hsiang Chang \\ Department of Industrial Design, \\ National Cheng Kung University, \\ Tainan, Taiwan \\ s.jautrein@gmail.com
}

\begin{abstract}
In today's highly competitive market environment with short product life cycles, the design of a product must not only satisfy the quality and the needs of customers but also ensure it has innovative values included. Therefore the study present a design process by the case of the electric scooter which is based on the concept of concurrent design. In the method, Objective Tree Analysis is first applied to identify the functions and establish the design criteria. Then, the Morphological Chart Method is applied to generate and visualize design alternatives. Analytic Hierarchy Process (AHP) and PUGH Concept Selection are applied to analyze and evaluate design details and obtain the optimal design concept. In this manner, an innovative electric scooter with a higher competitiveness among the current market is designed which is more nearly fits consumers' needs and the total quality is managed after the design process has been completed.
\end{abstract}

Keywords-concurrent design; electric scooter; objective tree analysis; orphological chart method; analytical hierarchy process

\section{INTRODUCTION}

With the improvement of technology and the rising awareness of the global environment, the population of electric scooter user has a rapid growth during the past decade. In China, under the circumstances of the enforcement of National III emission standards as well as the rising market demand for motor vehicles, electric vehicles and other substitutes, motorcycle enterprises of China are facing the pressure of product structure adjustment [1]. Electric scooter takes the advantage of the eco-friendly design, a study showed the energy use of an electric scooter was 2.9 times and 6.1 times less than the petrol motorcycle and car, respectively. Furthermore, the total operating costs (electricity and battery replacement) of an electric scooter was also $24 \%$ greater than the best-selling equivalent petrol motorcycle and 1.7 times lower than the best-selling car [2]. The main purpose of the study is to develop an innovative electric scooter design by utilizing the approach of concurrent design in order to reach its highly competitive marketplace [3]. Manage to clarify the future trend of electric scooter market, current models are surveyed and the sales result are also taken into account at the beginning [4]. Through literature reviews, Objective Tree Method is applied to identify the functions and design limit, therefore the design criteria of the product can be established.
Morphological Chart Method is used to generate a series of design alternatives through changing design components of different parts [5]. Then, Analytic Hierarchy Process is applied to calculate the weight of design criteria which allows the study to evaluate all the design alternatives by using PUGH Concept Selection. Therefore, an innovative design of electric scooter with high competitiveness is obtained by the complete of the design process [6].

\section{THEORETICAL BACKGROUND}

\section{A. Objective Tree Analysis}

Objective Tree Analysis is a hierarchy technique providing an overview of the problem and the corresponding solutions and objectives. Once the problem is identified, possible solutions are listed at the second level as branches, therefore the objective tree is established. To make the solutions more specific, the third level can be established by decomposing each solution into sub-solution. Besides the result includes a wide variety of design details, design limits and design criteria can also be established in the process. In this study, Objective Tree Analysis is applied to identify the design details and features of the electric scooter.

\section{B. Analytical Hierarchy Process}

Analytic Hierarchy Process is a structural method in order to analyze and make complex decisions under the evaluation of multi-criteria, proposed by Saaty ( Satty, 1980 ) [7,8,9]. The method aims to clarify the relation and the priority of considered criteria which further during the process of hierarchical structure, the best solution can be obtained. In this study, Analytical Hierarchy Process are applied to analyze the correlation between each component and organize the design priority of each of them.

\section{Morphological Chart Method}

The purpose of Morphological chart method is to list those essential aspects that must be incorporated in the product, or that it must be capable of serving as a function [10]. Variations can be provided by listing design ideas for each individual component. Therefore, a variety of design 
TABLE I. MARKET SURVEY

\begin{tabular}{|c|c|c|c|c|c|c|}
\hline Model & $\begin{array}{c}\text { e-moving } \\
\text { EM80 }\end{array}$ & $\begin{array}{c}\text { GOGORO } \\
\text { gogoro plus }\end{array}$ & $\begin{array}{c}\text { Kymco } \\
\text { Candy EV }\end{array}$ & Kentfa & Yamaha \\
& &
\end{tabular}

alternatives can be obtained by recombining different possible elements to make a solution. The method deals with a large number of combination and not only include existing or conventional solutions, novel solutions can also be discovered

during the process. The study adopted Morphological Charts Method to generate various alternatives of the overall structure of electric scooter.

\section{PUGH Concept Selection (Decision-matrix method)}

Proposed by Pugh ( Pugh, 1981 ), PUGH Concept Selection it is a quantitative technique used to evaluate design alternatives by the criteria from different dimensions $[11,12]$. Also known as the decision-matrix method, a weighted decision matrix with several design concepts is established at the beginning. The concept of current design will be selected as the original DATUM and each design concept will be evaluated relative to the original DATUM. Instead of comparing among themselves, design alternatives are only individually and separately compared with the DATUM.

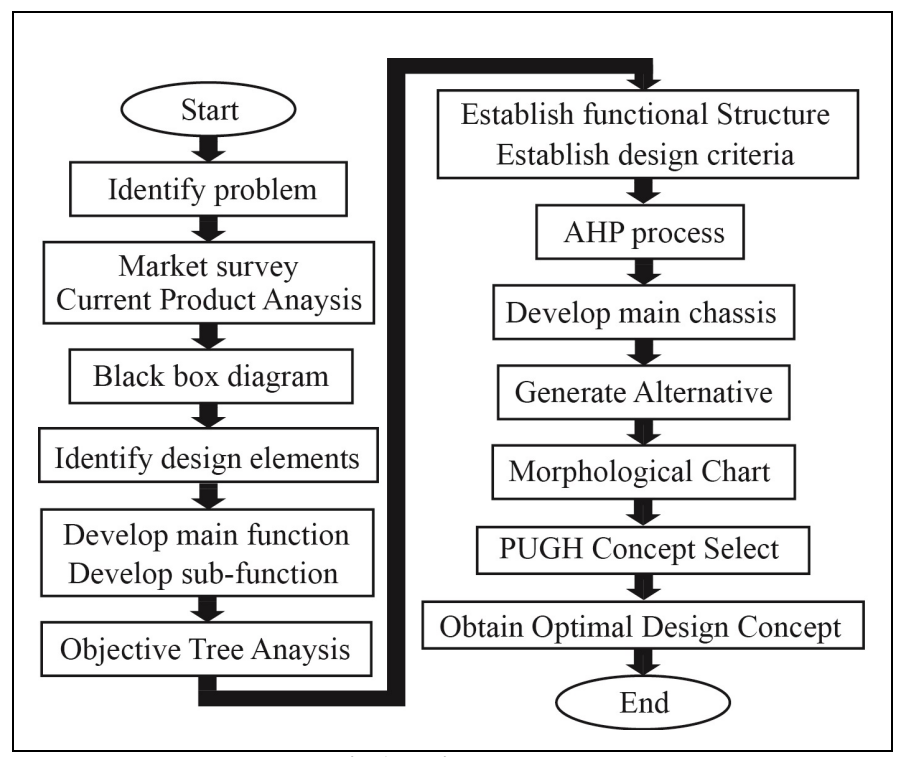

Following rules are made for the evaluating process: "+" means the concept is better than the DATUM. "-" means the concept is not as good as the DATUM. "S" means the concept is about the same performance as the DATUM or it cannot be compared since doubt exist. The design rating is calculated by multiplying "+" as 1, "-" as -1 , "S" as zero with its corresponding weight of considered criteria in each column. By adding up the total score of each design concept, the concept which has the highest score will be selected as the preferable design alternative. In this study, PUGH Concept Selection is applied to converge the design alternatives and obtain the optimal design.

\section{CASE STUdy}

\section{E. Design Process}

The study demonstrates the design strategy based on the concurrent design in the case study of electric scooters. The design process of the study is shown in Fig.1 [13].

\section{F. Market Survey and Trend Prediction}

Although the market of electric scooter has a massive growth since it first came out, the development of electric scooter has come to a halt for the past few years. According to the survey of the current model and the sales report in Taiwan [14], it can be found that outstanding performance electric scooters reach a high market share among other models in these days, shown in Table 1. According to report shown in Table 2, Even though the overall sales volume is increased due to the release of high performance electric scooter, the market of low-end models is still shrinking. In conclusion, the highend product which with high-performance and high price has its potential and will soon become the market trend in the future. 
TABLE II. ELECTRIC SCOOTER SALES REPORT IN TAIWAN

\begin{tabular}{|c|c|c|c|c|}
\hline & $\begin{array}{c}2015 \\
\text { Sales } \\
\text { Volume }\end{array}$ & $\begin{array}{c}2016 \\
\text { Sales } \\
\text { Volume }\end{array}$ & $\begin{array}{c}\text { 2015 Sales } \\
\text { Percentage }\end{array}$ & $\begin{array}{c}\text { 2016 Sales } \\
\text { Percentage }\end{array}$ \\
\hline Kymco Inc. & 885 & 722 & $15.60 \%$ & $5.10 \%$ \\
\hline $\begin{array}{c}\text { Yamaha } \\
\text { Taiwan }\end{array}$ & 224 & 476 & $4.00 \%$ & $3.40 \%$ \\
\hline $\begin{array}{c}\text { Sanyang } \\
\text { Industry }\end{array}$ & 33 & 190 & $0.60 \%$ & $1.30 \%$ \\
\hline e-moving & 4,124 & 3,401 & $72.90 \%$ & $24.10 \%$ \\
\hline $\begin{array}{c}\text { Kentfa } \\
\text { Advanced } \\
\text { Technology } \\
\text { Corp. }\end{array}$ & 0 & 303 & $0.00 \%$ & $2.10 \%$ \\
\hline $\begin{array}{c}\text { Tong Geng } \\
\text { Enterprise } \\
\text { co. }\end{array}$ & 338 & 2 & $6.00 \%$ & $0.00 \%$ \\
\hline GOGORO & 0 & 8984 & $0.00 \%$ & $63.60 \%$ \\
\hline Kuan Mei & 56 & 53 & $1.00 \%$ & $0.40 \%$ \\
\hline Total & 5660 & 14131 & & \\
\hline
\end{tabular}

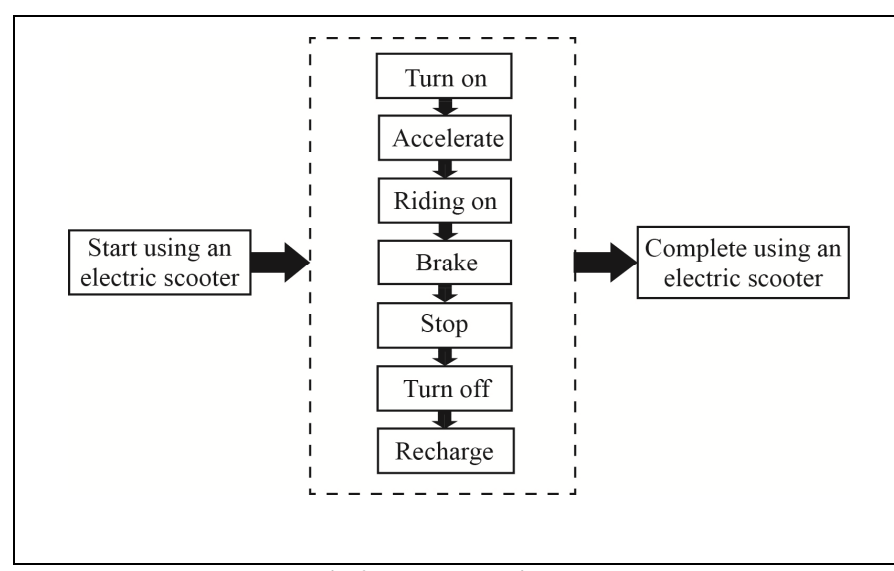

Fig.2 Black box diagram

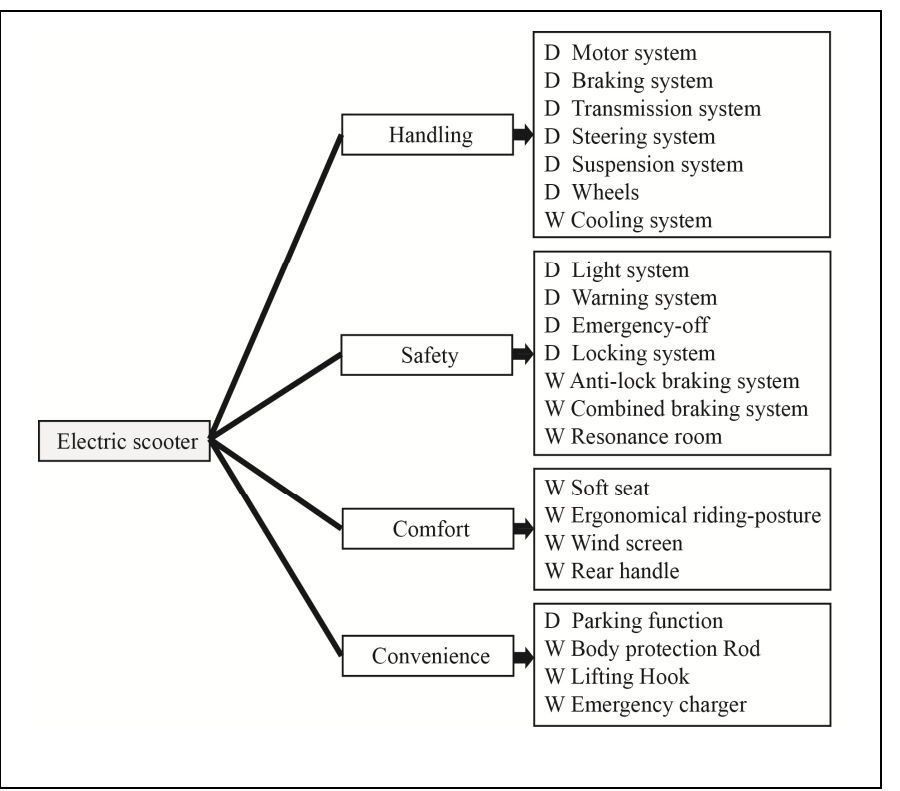

Fig.3 Identify design elements

\section{G. Black box Diagram}

Black box diagram is used to clarify the procedure hidden between the input and the output of the electric scooter. The desired using process is shown in a "black box" process in Fig.2

\section{H. Identify design Elements}

In the early stage of the design process, it is important to identify the design elements. By applying Objective Tree Analysis, shown in Fig.3, the design objective is divided into 4 categories, including handling, safety, comfort, and convenience. Furthermore, design elements are listed to give more details for satisfying the objectives. D and W which shown in the figure, representing "Demand" and "Wishes" which indicates the necessity of the elements

\section{Establish design criteria}

To establish the design criteria, Objective Tree Analysis is also applied in this step. According to the analysis, the design objectives transform into the design orientations and then diverge into 22 design criteria which shown in the functional structure as Fig.4. The design criteria also mean the standard feature and equipment of the electric scooter which must be followed during the following process.

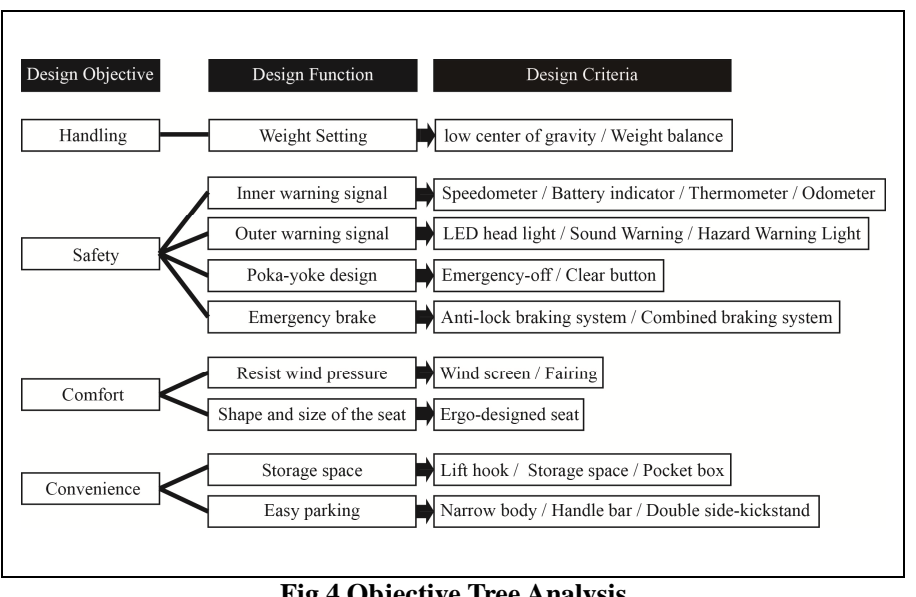

Fig.4 Objective Tree Analysis

\section{J. Main chassis denelopment}

In order to simplify the overall design process of an electric scooter, the task of developing the main chassis has to be in the first place. Considering there are plenty design factors and components to assemble an electric scooter, it is important to find the correlation and the design order of each component. Shown in Table 3, by evaluating the value of each component, the comparison matrix is built.

Analytical Hierarchy Process converts these value into a numerical weight or priority. According to the analysis shown in Table 4, the frame has the highest weight of 0.15775 which beyond other components. Besides, the values of D-value and $\mathrm{R}$-value for each component is also calculated based on the 
TABLE III. COMPARISON MATRIX OF COMPONENTS

\begin{tabular}{|c|c|c|c|c|c|c|c|c|c|c|c|c|}
\hline & Frame & Wheels & $\begin{array}{c}\text { Front } \\
\text { Suspension }\end{array}$ & $\begin{array}{c}\text { Rear } \\
\text { Suspension }\end{array}$ & Motor & Battery & $\begin{array}{l}\text { Rider } \\
\text { Posture }\end{array}$ & Seat & Grip & $\begin{array}{l}\text { Wheel } \\
\text { base }\end{array}$ & $\begin{array}{l}\text { Trans- } \\
\text { mission }\end{array}$ & Handling \\
\hline Frame & 1 & 1 & 1 & 3 & 4 & 4 & 2 & 2 & 1 & 2 & 3 & 3 \\
\hline Wheels & 1 & 1 & 1 & 1 & $1 / 2$ & 1 & 1 & 1 & 1 & 0.5 & 0.5 & 1 \\
\hline $\begin{array}{c}\text { Front } \\
\text { Suspension }\end{array}$ & 1 & 1 & 1 & 1 & 1 & 1 & 1 & 1 & 1 & 1 & 1 & 2 \\
\hline $\begin{array}{c}\text { Rear } \\
\text { Suspension }\end{array}$ & $1 / 3$ & 1 & 1 & 1 & $1 / 4$ & $1 / 3$ & 1 & 1 & 1 & 3 & 1 & 2 \\
\hline Motor & $1 / 4$ & 2 & 1 & 4 & 1 & 2 & 1 & 1 & 1 & 1 & 4 & 1 \\
\hline Battery & $1 / 4$ & 1 & 1 & 3 & $1 / 2$ & 1 & 1 & 1.5 & 1 & 1 & 1 & 3 \\
\hline Rider Posture & $1 / 2$ & 1 & 1 & 1 & 1 & 1 & 1 & 2 & 2 & 1 & 1 & 3 \\
\hline Seat & $1 / 2$ & 1 & 1 & 1 & 1 & $2 / 3$ & 0.5 & 1 & 1 & 1 & 1 & 2 \\
\hline Grip & 1 & 1 & 1 & 1 & 1 & 1 & 0.5 & 1 & 1 & 1 & 1 & 1 \\
\hline Wheel base & $1 / 2$ & 2 & 1 & $1 / 3$ & 1 & 1 & 1 & 1 & 1 & 1 & 1 & 3 \\
\hline Transmission & $1 / 3$ & 2 & 1 & 1 & $1 / 4$ & 1 & 1 & 1 & 1 & 1 & 1 & 1 \\
\hline Handling & $1 / 3$ & 1 & $1 / 2$ & $1 / 2$ & 1 & $1 / 3$ & $1 / 3$ & $1 / 2$ & 1 & $1 / 3$ & 1 & 1 \\
\hline
\end{tabular}

TABLE IV. ANALYSIS OF THE COMPARISON MATRIX

\begin{tabular}{|c|c|c|c|c|}
\hline & $\begin{array}{l}\mathrm{D}+\mathrm{R} \\
\text { value }\end{array}$ & $\begin{array}{c}\text { Geometric } \\
\text { mean }\end{array}$ & Weight & $\lambda \max$ \\
\hline Frame & 34 & 1.97188 & 0.15775 & 13.74224981 \\
\hline Wheels & 25.5 & 0.84089 & 0.06727 & 13.00896411 \\
\hline Front Sus. & 24.75 & 1.05946 & 0.08475 & 12.34856269 \\
\hline Rear Sus. & 30.75 & 0.86129 & 0.06890 & 14.07981961 \\
\hline Motor & 31.75 & 1.2599 & 0.10079 & 14.34546208 \\
\hline Battery & 29.58333 & 1.04456 & 0.08356 & 13.14980561 \\
\hline $\begin{array}{c}\text { Rider } \\
\text { Posture }\end{array}$ & 26.83333 & 1.16103 & 0.09288 & 12.5201377 \\
\hline Seat & 25.66667 & 0.91251 & 0.07300 & 12.23892216 \\
\hline Grip & 24.5 & 0.94387 & 0.07551 & 12.62804055 \\
\hline Wheel base & 20 & 1 & 0.08000 & 12.94664687 \\
\hline $\begin{array}{c}\text { Transmissi } \\
\text { on }\end{array}$ & 2808333 & 0.86129 & 0.06890 & 12.86564287 \\
\hline Hand ling & 30.83333 & 0.5830 & 0.04664 & 13.0890478 \\
\hline Sum & \multicolumn{2}{|c|}{12.4998} & $\begin{array}{c}\text { Average } \\
\lambda \max \end{array}$ & $\begin{array}{c}=13.0802751 \\
5\end{array}$ \\
\hline \multicolumn{3}{|c|}{ C.R.=C.I./R.I. } & \multicolumn{2}{|c|}{$=0.06377<0.1 \rightarrow \mathrm{OK}$} \\
\hline
\end{tabular}

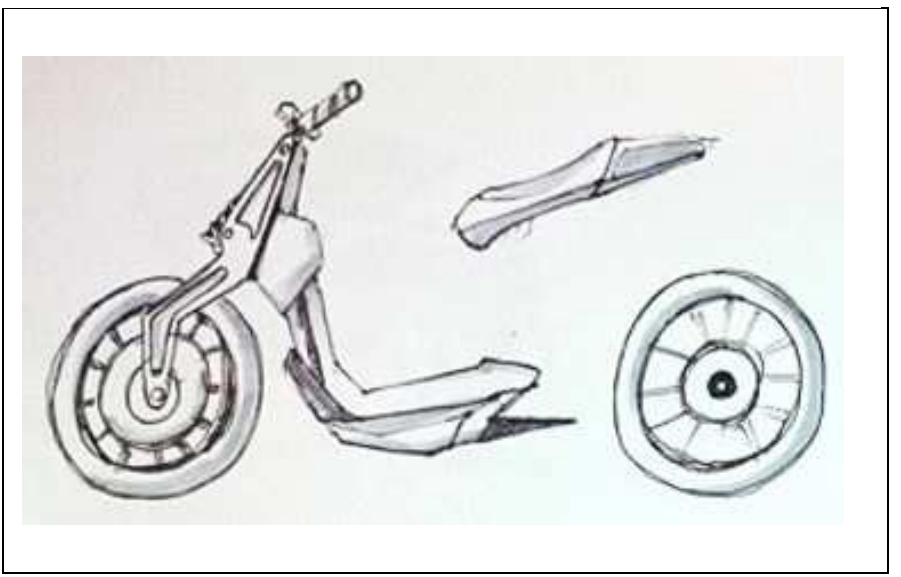

Fig.5 The main chassis of the electric scooter

concept of Interpretive Structural Model [15]. The D+R value shows the sum of interactions of a component. With a low $\mathrm{D}+\mathrm{R}$ value, the component is indicated to be individual and is rarely relevant to other components. In this situation, it is acceptable to progress all the design process of individual parts simultaneously. The result reveals that the lowest $D+R$ value is 20 for the wheelbase and other components such as wheels, front suspension, seat, and grip also have a low D+R value which is $24.5,24.5,25.67 .24 .5$, respectively. In this manner, the main chassis of the electric scooter is developed by the process which is shown in Fig.5, including frame, wheels, front suspension, seat, grip, and wheelbase. 


\section{K. Generation Alternatives}

To fit the motor, the battery, the transmission and the rear suspension into the main chassis, Morphological Chart is used to generate structure alternatives. Plenty sets of design concept can be generated theoretically by applying the method. However, considering its possibilities, only 14 alternatives are chosen as the possible solutions which are shown in Fig.6. Nevertheless, the concept which features a front-wheel motor and a low arrangement of the battery is chosen, due to its balanced weight between front and rear and the rather large storage place under the seat. The complete structure is shown in Fig.7

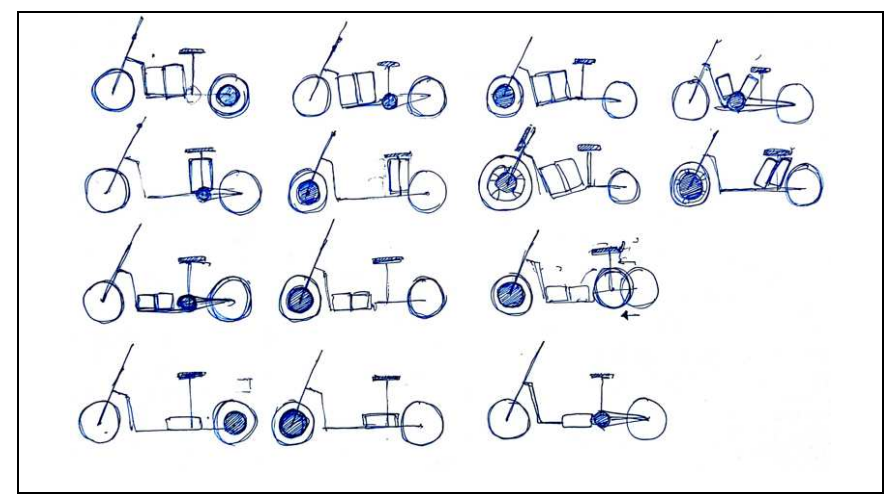

Fig.6 The structure alternatives generated

by Morphological Chart Method

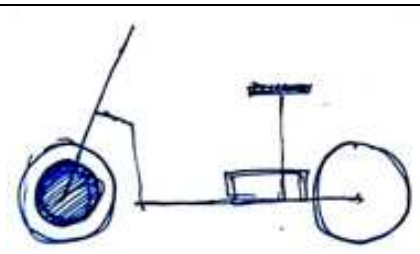

Fig.7 the complete structure of the electric scooter

\section{PUGH Concept Selection}

Based on the fundamental structure and the chassis concept shown in Fig.7, the electric scooter is further developed into 5 different styles considering different purpose and scenario which are shown in Fig.8 [16]. To obtain the optimal design concept with high competitiveness among the current market, PUGH Concept Selection is applied to evaluate these design concept. The design concept which shares a similar design orientation with its target rival: GOGORO is chosen as the DATUM for the evaluating process. 8 evaluate criteria are identified and they are shown in Table.5 and the process of PUGH Concept Selection is shown in Table 6.

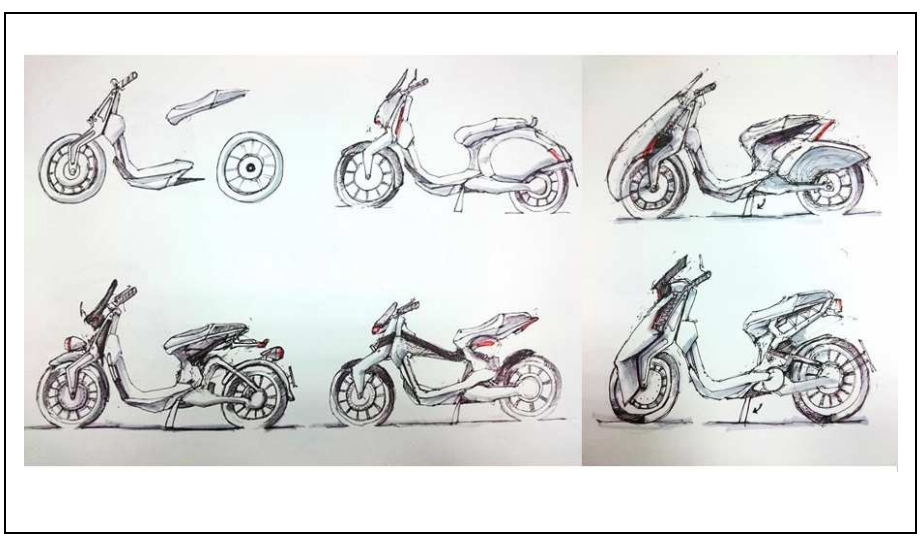

Fig.8 Design concept of electric scooter

TABLE V. EVALUATE CRITERIA FOR THE PUGH CONCEPT SELECTION

\begin{tabular}{|c|c|}
\hline Meet consumers' need & Easy to maintain \\
\hline Suitable for daily use & Comfort level during ride \\
\hline Innovative body design & Easy to move when parking \\
\hline Sufficient storage place & Easy to identify at night \\
\hline
\end{tabular}

TABLE VI. PUGH CONCEPT SELECTION

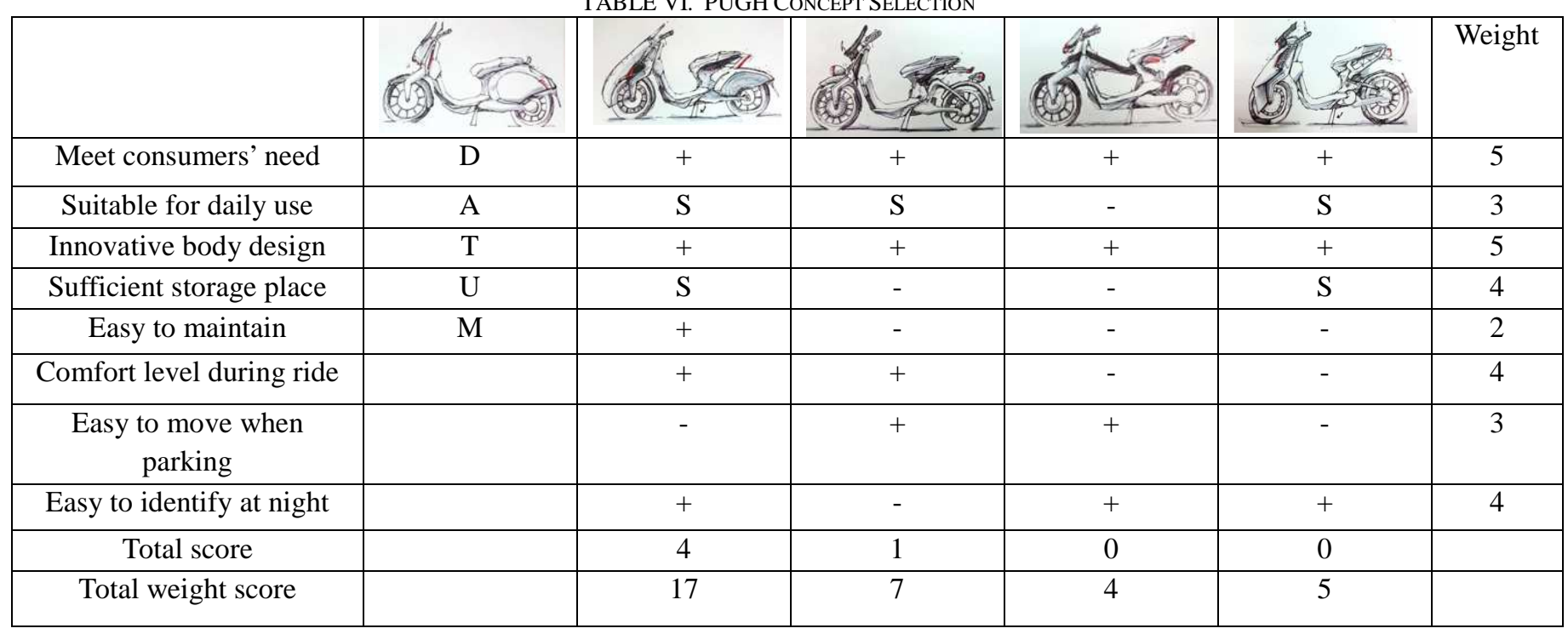




\section{Optimal Design Concept}

By applying PUGH Concept Selection, the concept which has a smooth body shape and huge front fairing are regarded as the optimal design concept. For more detail design shown in Fig.9, a 1/12 model is built which is shown in Fig.10.

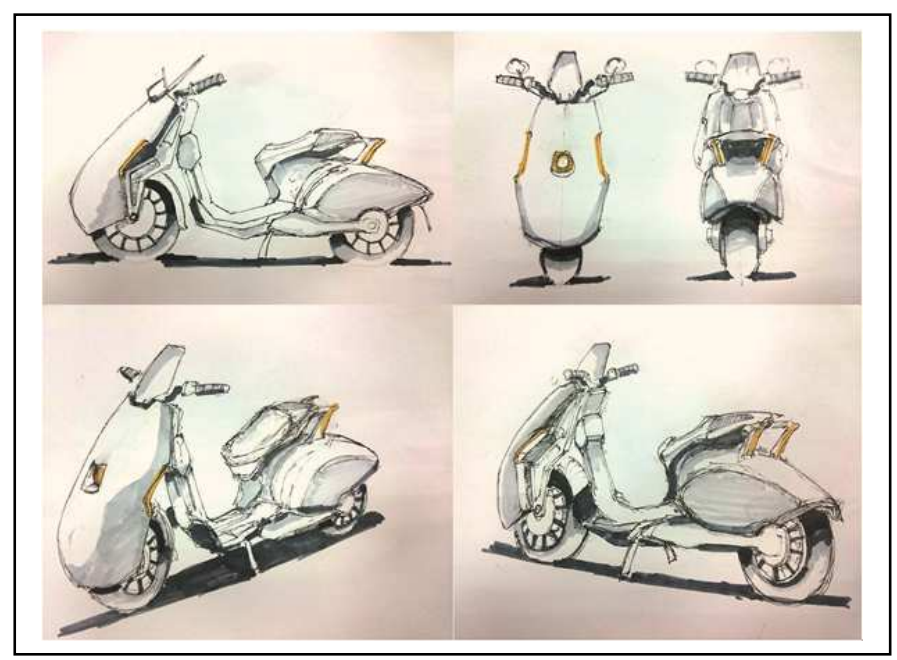

Fig.9 Sketches of the final design concept

\section{RESULT}

The final design of the electric scooter is mainly focused on the uprising high-end markets. In addition to adding new technology, the design of the bodywork has adopted the concept of the classic scooter which is contained smooth figure and an elegant product image. The features of the final design are:

(1) Front-wheeled drive, which gives a sensitive steering increase its agility. Moreover, the weight of front and rear are well-balanced.

(2) Narrow profile, which is suitable for riding through traffic jams and finding a parking place in the urban area.

(3) Frontal double-wishbone suspension, solving the problem of traditional shock absorbers due to the unequal operation of left and right, enhancing the stability.

(4) Large fairing, not only resists the wind flow for the riders, it also enhances the aerodynamics and has a significant improve in energy saving.

\section{CONCLUSION}

The study represents the case design of electric scooter by applying concurrent design strategy. Through the design process, various method and approach are used to help designers to clarify the problem hidden inside the black box furthermore to reach the optimal solution. The process is also suitable for fast design. Business and companies feel trustworthy when the design process is visible and the overall design quality is manageable. Moreover, the design process can be modified for different situation, which makes the user more confident when facing market change by having more efficient control in developing products.

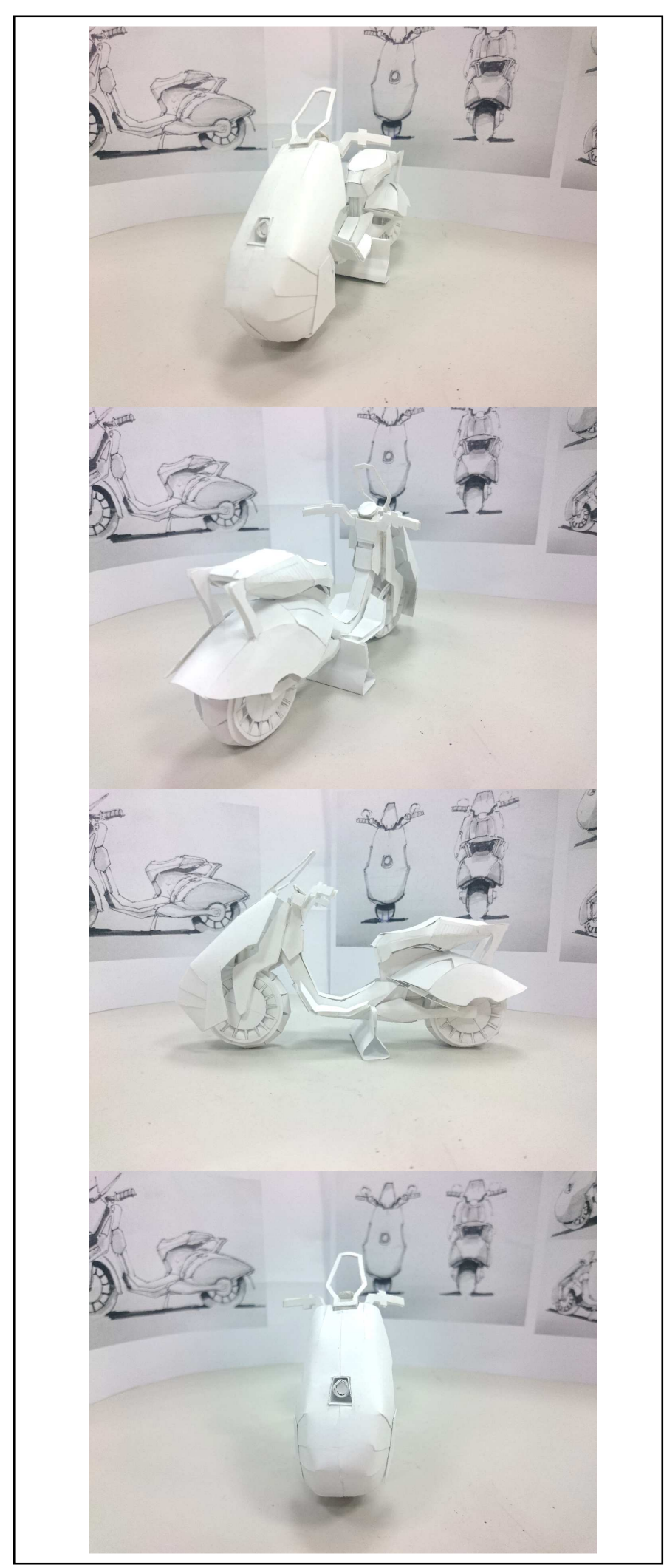

Fig.10 A 1/12 model of the final design concept 


\section{References}

[1] Research in China, Global and China Motorcycle Industry Report, 2012.

[2] Justin D.K. Bishop, Reed T. Doucette, Daniel Robinson, Barnaby Mills, Malcolm D. McCulloch, "Investigating the technical, economic and environmental performance of electric vehicles in the real-world: A case study using electric scooters,". Journal of Power Sources, vol. 196, issue 23, pp. 10094-10104, 2011.

[3] S. W. Hsiao, "Concurrent design method for developing a new product," International journal of Industrial Ergonomics, vol. 29, pp. 41-55, 2002.

[4] S. W. Hsiao, "Integrated FSM - STM and DFA Method to Faucet Design," Journal of the Chinese Institute of Industrial Engineers, vol. 13, No. 3, pp. 225-23, 1996.

[5] Nigel Cross, Engineering Design Methods: Strategies for Product Design, John Wiley \& Sons, USA, 2000.

[6] S. W. Hsiao, J. R. Chou, "A creativity-based design process for innovative product design," International Journal of Industry Ergonomics, vol. 34, pp. 421-443, 2004.

[7] Bin Liu, Fanjun Kong, "Research and application of sidewall stability prediction method based on analytic hierarchy process and fuzzy integrative evaluation method," Natural Science, vol. 4, No. 2, pp. 142147 RI1.54, 2012.
[8] S. W. Hsiao, Y. C. Ko, C. H. Lo, S. H. Chen, "An ISM, DEI, and ANP based approach for product family development," Advanced Engineering Informatics, vol. 27, issue. 1, pp. 131-148, 2013

[9] T. L. Saaty, "The Analytic Hierarchy Process," McGraw-Hill, New York, 1981.

[10] G. Pahl, \& W. Beitz, Engineering Design: A Systematic Approach, Chapter 3: The design process, Design Council, London, 1996

[11] S. Pugh, "Concept Selection - A Method That Works", Proceedings, International Conference on Engineering Design, March 9-13, 1981.

[12] B. Lee Tuttle, "Design for Function: A Cornerstone for DFMA," International Forum on Product Design for Manufacture and Assembly, Newport, RI, 1991.

[13] N. F. M. Roozenburg, J. Eekels, Product Design: Fundamentals and Methods, John Wiley \& Sons, USA, 1995.

[14] Green car sales report from Environmental Protection Administration, http://greencar.epa.gov.tw/introduction/emobile.aspx?type=6

[15] S. W. Hsiao, Elim. Liu, "A structural component-based approach for designing product family," Computers in Industry, vol. 56, pp. 13-28, 2005.

[16] Café racer, scrambler and custom motorcycles, Bike EXIF, http://www.bikeexif.com/ 